\title{
Information keys of the education system
}

\author{
Valentin Tkachev ${ }^{1, *}$ \\ ${ }^{1}$ National Research Moscow State University of Civil Engineering, 129337, Yaroslavl sh., D. 26. , \\ Moscow, Russia
}

\begin{abstract}
The progress of a technical civilization as a product of the development of social mentality is based on the synthesis of three components: a pair of respondents connected by means of communication which in general is a single historically formed aggregate of cultural progress. The mechanism of action of this aggregate: the first respondent, who has accumulated the potential for useful achievements, transmits information through direct and feedback channels to the second respondent, who implements the received information about achievements, sending signals to the first to request updates and improvement of activity. The phenomenon of the evolutionary ladder is formed, the steps of which are the progress of civilization, imitated in a playful form by the educational system that supplies the society with trained specialists. Ideally, a professional school of the middle and higher levels is focused on the production of personnel with developed creative inclinations. However, in practice, special educational institutions produce specialists who are mainly ready for reproductive work. And only a small proportion of graduates, immediately after graduation or after working in the field of routine production, reveal their creative and organizational potential. The introduction of electronic information technology into education, furthermore stimulated by the requirements of self-isolation due to the pandemic, brings the problems of distance learning to the surface of professional education.
\end{abstract}

\section{Introduction}

Information as a key tool of social communication acquired officially enshrined educational functions already in the era of antiquity, first in the implicit form of accompanying Socrates by curious Athenians, the accumulation of knowledge by Greek philosophers in travels in the East (the mysterious Maghrib, the land of fakirs), and finally, in oratory schools, where the most famous masters Plato and Aristotle gave conversation classes, strolling in the gardens of the Academies.

Of course, didactic texts inspired by sophistry and Socratic mentoring, written by diligent students and competing philosophers already appear.

The educational system in special institutions, and more often at the master's home, was first formed according to the formula "shoemaker - apprentice", in which the student accumulated versatility of knowledge and skills independently, to the best of his ability.

\footnotetext{
* Corresponding author: valentintn@mail.ru
} 
We are not aware of any other methodology for obtaining high qualifications by ancient sculptors, architects and Renaissance painters; the mysterious origins of the tectonic literacy of Isidore and Anthemius, who erected Hagia Sophia in Constantinople; mysticism hides the amazing secrets of the skill of the French Masons, the creators of the dark fabulousness of the Gothic cathedrals. Historians were of little interest in this area of gaining professionalism. Perhaps, except for information about the Paganini's father savage methods of teaching, and Tibetan albums with samples of drawings of Buddhist icons.

How did they learn to master the skills of creating perfect forms? Where are their student exercises? Destroyed?

And what about the cultural monuments of the ancient Egyptians, the Indians of Mesoamerica, the Chinese?

Where are the traces of learning a craft, understanding large-scale proportionality, educating fine taste and artistic views?

Craftsmanship was naturally passed down from generation to generation. Probably, not only from father to son, but also recorded on various media available to each era and, of course, in preserved masterpieces, canons, samples [1]. The canons of proportioning ancient Egyptian sculpture and, of course, the "Canon" of Polykleitos, Lysippos' recommendations for sculptors of the Hellenistic era have come down to us.

The stages of mastering information carriers were formed sequentially, in accordance with the achievements of technical civilization and the needs of society in expanding information horizons, through educational experiments.

Until the end of the 19th century, "manual" information technology prevailed, which is not forgotten even today. The mechanical means of recording and transmitting information at the beginning of the 20th century were quickly replaced by electrical systems (T. Edison and others), typewriters, then by a xerox, the first computer models, intriguing cryptographic records on paper tape.

At the end of the 20th century, a spontaneous growth of electronic technology in information systems began, programming the management of automated production with miniaturization of computer processors, revealing the boundless horizons of ownership of the technical and intellectual resources of civilization [2].

Let's step over the stages of the rapid improvement of devices for accumulating, recording and transmitting information - at least using the example of household, in fact, gaming devices - and turn to the modern phase of the progress of information technologies, the inevitability of which intrusion into the educational system led to its methodological crisis: synthesis (or mutual annihilation?) of "manual" (I suppose, no need to explain) and e-learning systems.

The crux of the matter is the way of exchanging information.

As the history of education has shown, direct, auditory contact has the advantages of transferring information "from hand to hand", and the listeners fixing the information flow created a stable mental connection between the brain and the recording hand (L. Levy-Bruhl). Archaic? Yes, of course. But this is exactly how, in the cooperation of both respondents (teacher and students), the works of the outstanding Swiss linguist F. de Saussure "Course of General Linguistics" [3] were formed; lecture notes of G.W.F. Hegel, written by students, transformed into the course "Aesthetics" [4]. The paradoxical statements of Socrates and Heraclitus "The Dark" were conveyed orally and in writing by philosophers who did not possess a developed associative imagination and were not shy about plagiarism.

The euphoria of the 20th century from the possibilities of packing all the information of the Brockhaus and Efron Encyclopedic Dictionary on a compact electronic disk or flash drive and the temptation to abolish the outdated book basis of education caused a reaction of sober scientists and writers to the haste of positive expectations from such progress. 
The plot of R. Bradbury's novel "Fahrenheit 451" metaphorically predicts the fate of a book-burning society. Here we can remember the story of a teacher who teaches classes on TV and secretly gathers students at home. She was exposed.

Perhaps these are just the fears of humanity, still living according to the concepts of the 20th century, which say: a person was created by labor in a team, and the desire to get rid of historical memory and the tension of the intellect leads him to degradation and exclusion from the competition for survival.

The architect P. Soleri warned about this [5], the thought of the danger of the cultivation of AI (artificial intelligence) was the final one in the life of astrophysicist S. Hawking [6].

Physical distancing of respondents increases the mobility of educational technology in time and space, and even its technical qualities. And for these advantages of localization of the teacher-student tandem, poorly measured and unforeseen losses should be sacrificed. There is a reason for discussion.

Another argument in favor of a dying tradition: the spatial separation of information exchange participants weakens the phenomenon of collective thinking ("here and now") during an active discussion of the topic as a reaction to the content of a lecture or a search for a solution ("brainstorming"). The psychological atmosphere of cooperative life in the common mental space disappears.

Tele and video conferencing can only partially fill this gap, although this technology is sufficient for solving simple educational tasks.

The crisis of the educational system, which can also be regarded as a growing pain, as a stage of connecting to more developed forms of intellectual service of the constantly growing demands of the consumer society, is a natural stage in the evolution of a technical civilization approaching its finish line [7].

The aberration (discrepancy) between the rapid progress of technology and the degradation of the human race, revealed by modern sociology, is even more obvious than the threat of an impending warming of the planet with the flooding of the oceans' coasts with the melting ice of Antarctica and Greenland. The teaching methods while walking in the Academy Gardens will never return.

And the task of reformers looking for ways to postpone the onset of the Apocalypse is to transform negative factors into an instrument of positive influence on circumstances.

After all, it has somehow worked out so far!

\section{Research materials and methodology}

So far, they rarely dare to publish forecasts of the social consequences of modern tensions in the world in the military and political, economic, and structural aspects.

And humanity, as before, carelessly accepts the blatant information about the imminent finale, remaining the zombie crew of the ship of fools.

Meanwhile, efforts are being made to level educational trails, conduct webinars, conferences, and congresses, which outline methods of painlessly introducing digital technologies into traditional teaching methods.

The author's long pedagogical experience in the system of higher architectural education makes it possible to conduct a historical inspection of methodological techniques, the results of which coincide with the studies of other authors who, based on the generalization of the survey results, reveal a tendency towards a drop in the tone of students' interest in learning, a loss of respect for the system of university education itself, which is acquiring more and more obvious signs of bureaucratization, saturation of educational programs with ballast disciplines. It is surprising that at the same time, high-class scientific research is being carried out at the institutes, on top of the education system. 
Attempts by universities to independently decide on educational technology run up against the Ministry of Education and Science's threats to cut the budget. The ministry's desire to integrate the education system by lining up universities in different sectors in a row once led to attempts to impose the obligation on technical and humanitarian universities to practice the same training programs in their first years. The illusion of the success of introducing computer literacy into school education in the distant northern cities of the Russian Federation is still maintained, although this, apparently, is inevitable. However, young active university workers are developing updated teaching models not only in universities in the European part of the country $[8,9,10,11,12,13]$.

The paper includes a number of theses aimed, in the author's opinion, at overcoming the impasse of modern professional education - at least at demonstrating this need.

\section{Research results}

Let us first point out the importance of the factor of psychological coordination of the respondents. The success of training is generated by the interest, motivation, and orientation of the student in choosing a profession. A preliminary stage of readiness to "get used to" the profession, achievement of a certain level of mental maturity is necessary. It is generally accepted that the psychological attitude to the profession is usually inherited in families of creative activity, but this is not necessary, a stable "guild" devotion to any occupation is important.

The conscious formation of his intentions is built in a young person by a stepwise system of getting used to: games in kindergarten - a school club and a favorite subject - college university.

A good school of maturity is pre-university work in a related specialty. It is useful for a future architect or civil engineer to work for a year or two on a construction site. This forms his social maturity, pragmatism of character, excluding formalistic mischievous tricks in learning and creative activity after graduation.

High school graduate who was brought to university by his parents will not get rid of infantilism soon, but there are a majority of them today, and the coincidence in time of civil maturation and education will affect the graduate's professional inability to immediately join productive work. One of the methods of completing the studies is master's degree, which means two more years of forced attachment to the university. Many have already got a job, but the status supported by a higher-level diploma is important.

A student who is firmly focused on the goals of his education, is practical in distributing his attention to academic disciplines, skillfully combines distance and full-time forms of education, and is independent in planning the study regime.

The tendencies towards self-education are still constrained by the existing "institutional" system of knowledge provision and certification.

The technology of modular development of programs practiced in the West, which allows for "unattached" education, of course, has a tinge of formalism and rests mainly on the fanaticism of the "eternal student" mode. But with the formed educational resource in the form of an end-to-end training program, quite comfortable and productive models of independent learning in free mode are created.

Note that any technology of education is somehow compulsory: either the student himself makes efforts to comprehend knowledge, or he is forced to do so by the disciplinary regulations of the educational institution.

In these conditions, by the way, talent often ripens. For example, the harsh regime of Paganini's musical education. This is about the topic of educating a creative personality as the goal of education. We add that the best incentive for acquiring knowledge is the 
parsimony of the information provided, the need to search for it. Italian violinists were reluctant to share the secrets of their art with their students.

Society does not need an uncontrolled increase in the number of highly educated professionals. An overproduction of lawyers and economists suddenly emerged in Russia due to the boom in interest in these professions in the $90 \mathrm{~s}$, in the phase of the maturation of criminal capitalism.

The inertia of the paradigm of the reputation of the most educated country has led to a paradox - a cleaning lady with two or three university degrees. The aberration of necessity and redundancy still squanders the budgets of the institute's incubators for the maintenance and training of specialists that no one needs in the near future.

This begs the following trivial question - do we need so many universities (even those left after the recent purge of the commercial educational network)?

Quite often only the name of a respectable educational institution guarantees the capitalization of a diploma covering a failed specialist.

The "derailed" industry, severed industrial connections are no longer able to support an excessive number of fictitious diplomates, and simple economic logic will eventually force the list of sectoral educational institutions to be reduced. And also, to sharply increase the level of training of specialists in worthy universities, at the same time distantly serving those who want to get an education on their own, passing regular certification.

Strengthening the trend towards the introduction of distance education has already been supported by methodological proposals for a comprehensive solution to the problem of synthesis with traditional "manual" systems, appropriate in individual work with students, especially in the development of creative potential, skills of creativity [14].

The fact of being of a modern professional school - teachers of mature age have more capacious knowledge, which is useful for contact work in classroom mode (and with small groups), but difficultly master the computer language; young colleagues are undoubtedly better at manipulating electronic information systems. So, does it make sense to have two teachers during the class? It will be a good school for a young teacher and organizationally successful.

Measures of perfectionism in the professional training system are ineffective. The authors of the methodological developments insist on the inclusion of the concept of a unified information and educational space - in the preparation of educational materials for "condensed" packaging of content, scientific and practical level, in the development of methods for broadcasting information in person and remotely, creating conditions for the successful mastering of information and interactive communication, indicating the functioning of a well-functioning learning mechanism. Its principle of operation: the connection of everything with everything - integrity in the structure and operation of the entire system, no matter what elements and types of action it consists of. This principle, which is also used to characterize architectural systems, is commonly called emergence [15].

Emergence imputes not only transmitting functions to the process of information transmission. The physical zone of information transmission is also the sphere of its active transformation, often perversion and even programming of actions.

The fictional stories of the yellow press about the explosion of the towers of the World Trade Center in New York became the prerequisite for a real tragedy.

Various methods of creating a trusting image of dubious (fake) information zombify the population to the stage of collective insanity. In the middle of the last century, some jokers prepared a radio program based on the novel by H. Wells "War of the Worlds" about the attack of the Martians on the United States, which caused a terrible commotion in the country. And films about cosmic horrors - after all, they also affect many as credibility. 
The fake launched by the United States during the presidency of R. Reagan towards the USSR about the beginning of preparations for space wars provoked the Soviet Union to make large expenditures on "retaliatory" actions, which significantly weakened the country's budget.

It seems that the revitalization of the information boom about preparing expeditions for the privatization of nearby planets has the same goals.

Fears fueled by the media about an imminent global war, an asteroid collision convinces the impressionable people of the need to dig bomb shelters.

Educational information is not yet drawn into fake processes, but, of course, the realities of life indirectly affect the structure of curricula and their content.

It is clear that the information presented in the programs reflects the current level of development of science and is not the final point of the cognitive processes. Certain philosophical schools of medieval European universities defended their understanding of the universe from opponents with fists, and Catholics on St. Bartholomew's night - with daggers.

The acuteness of scientific disputes today has taken the form of journalistic discussions, less temperamental and politicized than the fight against the pseudosciences of cybernetics and genetics in the darkening era of the mid-20th century.

But ongoing or expected events of modern social life, planetary or cosmic catastrophes, as well as force majeure like a pandemic, are immediately introduced into the global information network, and, as a rule, in a negative way.

Similarly, educational information is rebuilt from a dry business presentation of materials to a lively style of spoken language with an abundance of illustrations, often of a humorous nature. This style of publications of serious textbooks and monographs must be taken into account, otherwise useful information will pass alongside the student's consciousness bypassing his thinking. Information in images is becoming one of the most effective forms of intellectual communication.

With remote transmission of information and the delayed time of its mastering, the fading effect appears, which is close to the phenomenon of the Weber-Fechner law of incomplete reproduction of signals.

In general, distance information is a factor of demobilization of the "average" student who is in no hurry to make efforts to master it, confident that he will always have time to do it.

The illusion of such knowledge "in the pocket" is supported by the accumulation of educational material, and on the test (exam), a nimble minded student will find the opportunity to "download" the necessary information and present it as a result of his studies without any effort.

The popular essay writing system based on the rich Internet resource is another form of documenting successful education. "Authors" of abstracts rarely get acquainted with their content.

As a result, there is a growing tolerance for the tendency of "pictorialism" of education, which can imperceptibly turn professional education into a cartoon, similar to that described by the Chinese writer Lao She in the novel "City of cats" (1932), where young cats receive higher education and diplomas the next day after enrolling in the university.

Thus, the problem of a conscious attitude to learning is not new, and people of purely parasitic inclinations are prone to the temptation to acquire prestigious diploma. There is also supply on demand.

Returning to the topic of reducing the number of universities and business revision of educational programs, it is possible to predict changes in the stratification of society, in which a narrow layer of the elite of truly top professionals with super productive thinking and capable of supporting scientific and technological progress in the global interests of a 
civilization torn apart by ambitions that will seem wild to our descendants, if they are lucky enough to be born.

Whether modern academies are capable of generating such scientists is a question, since for some academics, this institution is only the final destination for satisfying the itch of prestige.

The modern industrial (or post-industrial?) society with all its systems and institutions needs treatment, so here the emphasis is placed on the negative phenomena of civilization.

It is obvious that in educational structures that mirror the state of the environment on a reduced scale, one can try to model the means of health improvement.

\section{Conclusions}

After the problem of orientation when choosing an educational institution, there is a final difficulty - the upbringing of the creative thinking of a graduate of the so-called "creative" educational institution of the middle and higher level. Both general concerns about the state of the educational system and the specifics of the crisis of the modern architectural school in Russia are well known.

Let us briefly find out whether we are dealing with hopeless prospects for the profession or whether this is the next stage of growth pain caused by transformations in real architecture.

Without going into details, we will single out the main qualities of the architectural profession that make up the subject of study.

1. Congenital or educated attentiveness to the environment, the appearance and state of which prompts the actions of reproduction or transformation.

2. Observed and mentally corrected phenomena and objects are fixed by drawing, painting, models. A bridge between the adequacy of the plane image and volumetric nature is being built - in the future, this is one of the main professional skills of an architect.

3. Subconscious upbringing of a sense of human co-scale with the habitable space and its filling.

4. A developed sense of a complex of aesthetic categories: tectonics, rhythm and meter, proportions, composition, color, etc. - on which taste and reflection to the perfection of form are brought up.

5. Understanding the logic of functional relationships of the elements of an organized space.

6. The ability to insight is a non-trivial way of solving an architectural problem.

Obviously, they are all components of the developed personal professionalism of a human architect, different from the architectural creativity of inert nature and fauna, conditioned by centuries of genetics.

Initially, the habitat was the prerogative of the object of human adaptation: the history of architecture bears witness to this.

Modern architecture (skyscrapers, giant factories, dams) is losing its anthropometric features. The man in the modern city has become a stranger. And as a measure of scale, he is no longer of interest for an architect. Industrialization does not tolerate liberalism, and the architect is forced to obey to the scale of technical civilization.

The rapid development of construction technology and the emergence of new building materials are eliminating from practice the "manual" architecture of brickwork, plaster, sculptural details, also handmade. This architecture ended in the middle of the 20th century.

Progress is natural and architects themselves actively participate in its implementation, not suspecting that they are creating the prerequisites for their exclusion from the design and construction process. The creative potential of the architect is becoming unclaimed; it is being successfully replaced by computer modeling. 
How does this affect architectural education?

With the introduction of computer-aided design, the need for an architect as the central figure of the creative process decreases, especially since in practical activities, a large amount of work falls on the structural analysts, and design becomes the subject of the architect's work: selection of interior elements, accessories, lighting, painting - where you do not even need skills in drawing and composition; visual graphics, so important for the customer, are helpfully provided by the computer. It is enough to have good taste in choosing a solution from the proposed options, which is ensured by traditional architectural education.

In the meantime, architecture students successfully master the electronic technology of education and the transition to the implementation of a course project in computer graphics is perceived by them painlessly, even with preference for it, because the implementation of the project can take 20 times less time for reflection than for "manual" work.

This is not about the nostalgia for sketching with charcoal on tracing paper.

Relaxation in creative work entails euphoria of demobilization of professionalism, which is regarded as a triumph of technical civilization, which has endowed machines with creative consciousness. This happens in music, painting, literature. The possibility of creating not by human hands amazes the imagination and makes you forget about the need for education, especially since the authors of computer abstractions made on a whim have fantastic fees. It is immoral from the point of view of ordinary public opinion.

Is this a cultural progress or an aesthetic (at least) diversion?

Where do you think the demarcation line should run, separating the still existing traditional art from the pressure of clever crooks, if it was erased even in the Tretyakov Gallery in Moscow?

\section{References}

1. A.F. Losev, History of ancient aesthetics (early classics) (M.: VIL, 1963)

2. O.I. Pashchenko, The use of an interactive whiteboard in the modern educational process, Innovative approaches in the organization of the educational process at the university (Nizhnevartovsk, 2011)

3. F. de Saussure, Course in General Linguistics (M.: Sotsekgiz. 1933)

4. G.W.F. Hegel, Aesthetics, in 4 volumes, Vol. 1. (Moscow: Art, 1968)

5. Yu.S. Lebedeva, Architectural bionics (M.: Stroyizdat, 1990)

6. S. Hawking, L. Mlodinow, The grand design (M.: AST, 2008)

7. A.P. Nazaretyan, Non-linear future (M.: Argamak-media, 2017)

8. V.A. Krasilnikova, Informatization of education: conceptual apparatus, Informatization and education 4, 21-27 (2003)

9. I.I. Legostaev, On the basic laws of learning in distance education, Social and humanitarian knowledge 4, 206-217 (2006)

10. O.I. Pashchenko, Information technology in education. Tutorial (Nizhnevartovsk, Publishing house of the Nizhnevartovsk State University, 2013)

11. A.V. Solovov, Information technologies of teaching in professional training, Higher education in Russia 2, 31-36 (1995)

12. D.Sh. Matros, Fundamentals of the theory of informatization of the learning process, Pedagogy 6, 11-19 (2007)

13. M.A. Petrenko, Unified information space of an educational institution, Information resources of Russia 5, 14-16 (2008) 
14. M. Nelke, Technique of creativity (M.: Omega-L, 2009)

15. N.A. Salingaros, Anti-architecture and deconstruction (M.-Yekaterinburg, Armchair Scientist, 2007) 